\title{
Fresh formulae for portraiture
}

\author{
New portraits of physicists David Brewster and Peter Higgs show that naturalistic images \\ can find distinct ways to reflect scientists and their work, Martin Kemp explains.
}

Many portraits depict scientists just as they are, with nothing to tell us what the sitter actually does. This was the dominant mode for centuries, when the key ambition was to be shown as a 'gentleman'. Props could also be imported - a flask or telescope, say - to give a clue about the individual's field of excellence. Then, from the nineteenth century, particularly in photography, scientists began to be shown in their working habitats - sometimes even in action.

But these formulae have become tired. Can an artist find a way of making the format or nature of a portrait stand in a more imaginative relationship to the achievements and character of the individual scientist?

An extreme solution was presented by Marc Quinn's 'genomic portrait' of John Sulston, composed from the cultivation of a fraction of Sulston's own DNA, which involves no traditional 'likeness' at all (M. Kemp Nature 421, 416-420; 2003). Alternative solutions to the dilemma are posed by new portraits unveiled last year of two Scottish university scientists, one past and one present.

The historic image portrays David Brewster, a combative nineteenth-century authority on optics, biographer of Newton, pioneer of photography, and inventor of the kaleidoscope and lenticular stereoscope. It is by Calum Colvin, who specializes in his own kind of optical magic, and was displayed earlier this year at exhibition Natural Magic at the Royal Scottish Academy in Edinburgh.

Colvin characteristically creates large-scale colour photographs of elaborately staged setups. He assembles tableaux of objects, such as tables, chairs and smaller domestic items, much like a seventeenth-century Dutch painter of interiors. He then selectively covers their surfaces with painted marks in such a way that they assemble themselves into a quite different image when photographed from a specific viewpoint. On angled and curved surfaces, the technique required is that of anamorphosis - the trick of oblique perspective that was perfected during the sixteenth and seventeenth centuries.

The Brewster portrait is one of a series that extends Colvin's illusions into the arena of stereoscopy, which exploits our binocular vision to create a three-dimensional effect from twodimensional images. The series includes a portrait of Charles Wheatstone, Brewster's great

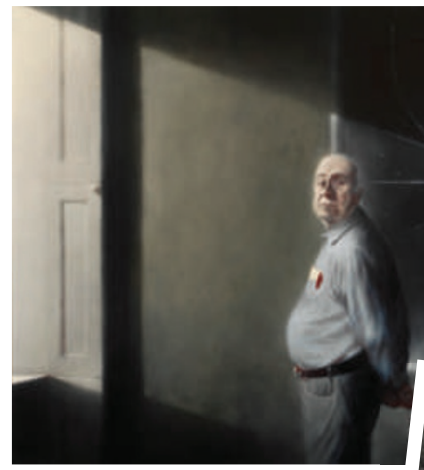

Portraits of theoretical physicist Peter Higgs (above) and kaleidoscope inventor David Brewster.

rival and adversary, the inventor of the stereoscopic viewer.

Resorting to the stereo technique simultaneously clarifies the three-dimensional reality of Colvin's arrays and masks the physical reality of the photograph itself as a surface. As he says, "I wanted to remove this physicality, making the images a form of 'mental construct."'

Looking through a lenticular viewer at two images of the Brewster portrait tableau photographed from separated viewpoints, we make out a ladder - for Colvin a symbol of intellectual ambition - and a clutter of objects specific to Brewster. The latter includes a stereo photograph of John Adamson, chemist and practitioner of photography in the Scottish town of St Andrews when Brewster lived there. In 1832, Brewster published his Letters on Natural Magic, addressed to the novelist and poet Walter Scott: Colvin has used Brewsterian magic to blend subject and scientific activity in a remarkable way.

The living scientist is Peter Higgs, the University of Edinburgh theoretical physicist famed for the boson that bears his name, devised to explain the mass of elementary particles. The search for the Higgs boson is one of the focuses of the Large Hadron Collider at CERN, Europe's particle-physics laboratory near Geneva, Switzerland, which is scheduled for relaunch in autumn, and is now looking over its shoulder at Fermilab in Batavia, Illinois. The painter of Higgs's portrait is Ken Currie.

The painting is set in Higgs's flat, one typical of Edinburgh's New Town district, which Currie describes as having "a very particular ambience - a greyish light illuminating the paraphernalia of his life". Among the paraphernalia are portraits of grandchildren below a massive mirror that is an original feature of the flat. The mirror itself is viewed from a standpoint equivalent to some 3 feet from the right edge of the canvas. In it we witness radiant traces of "the often very elegant movements of colliding particles".

Higgs, with his spectacles in hand behind his back and his eyes located precisely along the horizontal of the perspective, seems to be staring simultaneously at us and, in reflection, at the 'final proof', which exists in an undefined space on our side of the canvas. Currie plays on the contrast between the seeping natural light and the febrile brilliance contrived in the recording instruments of the collider. The one light is earthly; the other emanates from a "world that is sublime, awesome, strangely terrifying", in the painter's own words. A quotation from the seventeenth-century thinker Blaise Pascal haunted Currie's imagination while he was painting the portrait: "The eternal silence of these infinite spaces fills me with dread."

A sheet of paper and pen are tucked into the standing physicist's pocket, in contrast to the awesome technology deployed in the collider's search for elusive boson, buried in realms of the scientific sublime. This primitive equipment is, as Higgs told Currie, what he needs for his work as a researcher of pre-experimental concepts. In a sense the portrait presents us with this quest within Higgs's mind. It is suffused by the longing for discovery and proof that drives all scientific thought, whether theoretical or experimental.

During the twentieth century, portraiture of all kinds became deeply problematic, as the great majority of experimental artists moved away from naturalistic representation. There was reason to think that the painted portrait was dying as a major genre. What both these artists show, faced with the challenge of portraying scientists who are involved with different modes of seeing and visualization, is that the traditional portrait, like the novel, can be endlessly revitalized when form and content are reforged into new kinds of unity.

Martin Kemp is emeritus professor in history of art at the University of Oxford, Oxford, UK. 